\title{
M-Learning: The Usage of WAP Technology in E-Learning
}

\author{
doi:10.3991/ijim.v3i3.808
}

J. Al-Sadi, B. Abu-Shawar

Arab Open University, Amman, Jordan

\begin{abstract}
This paper presents the experience of Arab Open University; AOU for short; on using WAP technology in mobile learning; m-Learning. The goal is to enhance eLearning aspects of the existing learning management systems (LMS); e.g. Moodle. In addition to presenting technical aspects of the WAP, we also introduce the advantages and disadvantages of using WAP technology in the learning process. Furthermore, a description of AOU's learning management system with the outcomes of the tutors and students is introduced. This paper discusses also the suitability and feasibility of using WAP technology devices for distance learning in real-time.
\end{abstract}

Index Terms-e-Learning, m-Learning, WAP, CMC, LMS, Open source.

\section{INTRODUCTION}

As technology rapidly advances, new ideas for learning will also emerge. Computer-mediated communication (CMC) facilitates the development of such learning communities. In the broadest sense, CMC refers to any communication via computers; common applications include e-mail, online bulletin board, and online chat. The most important educational affordance of CMC lies in its connectivity: it connects learners at different geographical locations beyond the boundaries of classrooms; allows learners to exchange information within a short period of time synchronously or asynchronously; and provides the flexibility for one-to-one, one-to-many and many-to-many communication. Connectivity among learners is critical for a learning community, without which social construction of collective knowledge would be greatly impeded.

The growth of Internet-based technology have brought new opportunities and methodologies to education and teaching representing in e-learning, online learning, distance learning, and open learning. These approaches are typically use in place of traditional methods and mean that students deliver their knowledge though the web rather than face-to-face tutoring.

e-Learning is a new trend of education system, where students deliver their materials through the web. eLearning is the "use of internet technology for the creation, management, making available, security, selection and use of educational content to store information about those who learn and to monitor those who learn, and to make communication and cooperation possible." [1]

Kevin [2] addressed the benefits of e-learning for both parties: organization and learners. Advantages of organizers are reducing the cost in terms of money and time. Learning time reduced as well, the retention is increased, and the contents are delivered consistently. On another hand, learners are able to find the materials online regardless of the time and the place; it reduces the stress for slow or quick learners and increases users' satisfaction; increases learners' confidence; and more encourages students' participations.

New technologies such as Wireless Application Protocol (WAP), General Packet Radio Service (GPRS) and 3G (3rd Generation) technologies further augment the educational potential of CMC by allowing learners and tutors access to the Internet, anywhere and anytime, via the micro browser equipped mobile phone.

WAP technology and the concept of e-learning is an evolving trend in education at all levels. Even classrooms with younger children are benefiting from the use of handheld mobiles and laptop computers.

Recent advancement in mobile and wireless technology as basic requirements of WAP applications has helped to improve commerce [3, 4, 5, and 6] and services [7, 8]. Mobile technology is strategic to many organizations and activities [9, 10]. Education is no exception! The use of mobile technology has not only extended desktop-based online learning environment into the mobile and wireless channel but also enabled education to take place anytime, anywhere [11]. Educational materials can be delivered to students through mobile devices. Mobile technology can also be integrated into learning management system to improve interactivity in the classroom and also in distance learning.

Research into new WAP technologies that enhance instructional activities will continue to support the educational community as it embraces the idea of anytime, anywhere learning. E-learning is not just about readily accessible information; it opens up the possibility for the delivery of multimedia information, interactive learning and assessment, and real-time distance collaboration.

Applications of WAP technology in education can provide benefits to both students and educators. WAP technology provides greater flexibility in student learning. Students can have access to educational materials through their WAP enabled mobile devices, which enable them to learn as and when the need arises and when the time is right for them, no matter where they are, even when they are on the move. With mobile devices, educational materials are not only readily available to students but they can also be delivered to students based on their needs and preferences $[12,13]$.

Sharma and Kitchens stated that M- learning offers a unique opportunity for teachers and students in different kinds of learning environment settings. The unique feature of this mode of learning is that it enhances flexibility for students; however, it demands new pedagogies, and new 
approaches to deliver a course. If appropriately facilitated, m-learning helps learners in a great way by providing virtual classrooms on their mobile devices. Teachers will ultimately spend more time for course-delivery and follow-up as compared to traditional classroom method. In addition, teachers will have to provide a rich learning resource and environment, which in turn, contributes to the quality of learning [14].

In this paper, the technical overview of WAP technology is presented in section two. A full description of the Arab Open University (AOU) LMS is presented in section three. Sections four and five present the using of WAP technology including its requirements and benefits. Sections 6 concludes this paper and section 7 presents the future work.

\section{TECHNICAL OVERVIEW}

Wireless Application Protocol (WAP) is a secure specification that allows users to access information instantly via handheld wireless devices such as mobile phones, pagers, two-way radios, Smart phone and communicators.

WAP is designed to be user-friendly and innovative data applications for mobile phones easily. There are three types of terminals have been defined:

- Feature phones, which offer high voice quality with the capability of text messaging and Internet browsing;

- Smart phones, with similar functionality but with larger display.

- The communicator, which is an advanced terminal designed with the mobile professional in mind, similar in size to a palm-top with a large display.

WAPs that use displays and access the Internet run what are called micro browsers; browsers with small file sizes that can accommodate the low memory constraints of handheld devices and the low-bandwidth constraints of a wireless-handheld network.

WAP uses Wireless Markup Language (WML), which includes the Handheld Device Markup Language (HDML) developed by Phone.com. WML can also trace its roots to eXtensible Markup Language (XML). A markup language is a way of adding information to your content that tells the device receiving the content and what to do with it. The best known markup language is Hypertext Markup Language (HTML). Unlike HTML, WML is considered a Meta language. Basically, this means that in addition to providing predefined tags, WML lets you design your own markup language components. WAP also allows the use of standard Internet protocols such as UDP, IP and XML.

Although WAP supports HTML and XML, the WML language (an XML application) is specifically devised for small screens and one-hand navigation without a keyboard. WML is scalable from two-line text displays up through graphic screens found on items such as smart phones and communicators.

WAP also supports WML Script. It is similar to JavaScript, but makes minimal demands on memory and CPU power because it does not contain many of the unnecessary functions found in other scripting languages. Because WAP is fairly new, it is not a formal standard yet. It is still an initiative that was started by Unwired Planet, Motorola, Nokia, and Ericsson.

\section{Markup language migration}

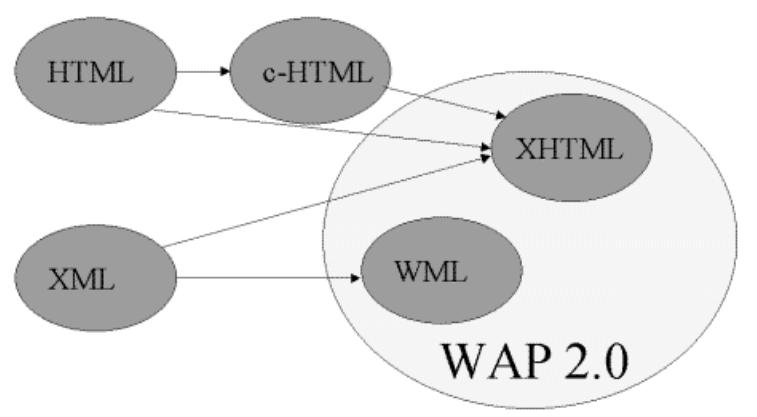

Figure 1. Migration of Markup language

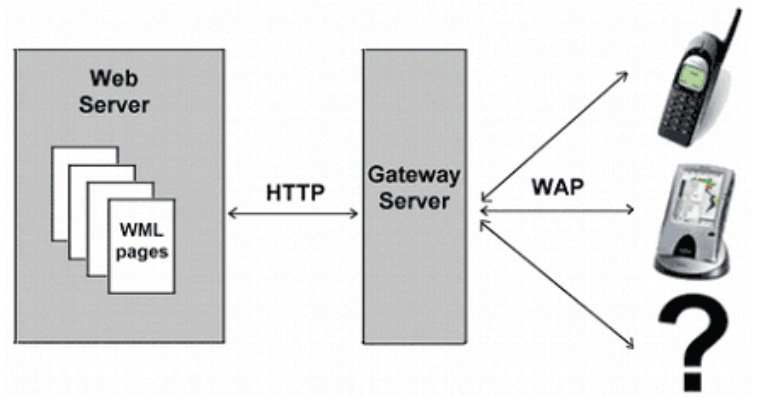

Figure 2. WAP Technology Infrastructure

There are three main reasons why wireless Internet needs the Wireless Application Protocol:

- Transfer speed: most cell phones and Web-enabled PDAs have data transfer rates of $14.4 \mathrm{Kbps}$ or less. Compare this to a typical modem, a cable modem or a DSL connection. Most Web pages today are full of graphics that would take an unbearably long time to download at $14.4 \mathrm{Kbps}$. In order to minimize this problem, wireless Internet content is typically textbased in most cases.

- Size and readability: the relatively small size of the LCD on a cell phone or PDA presents another challenge. Most Web pages are designed for a resolution of 640x480 pixels, which is fine if you are reading on a desktop or a laptop. The page simply does not fit on a wireless device's display, which might be $150 \times 150$ pixels. Also, the majority of wireless devices use monochrome screens. Pages are harder to read when font and background colors become similar shades of gray.

- Navigation: navigation is another issue. You make your way through a Web page with points and clicks using a mouse; but if you are using a wireless device, you often use one hand to scroll keys.

WAP takes each of these limitations into account and provides a way to work with a typical wireless device.

Here's what happens when you access a Web site using a WAP-enabled device:

- You turn on the device and open the mini-browser.

- The device sends out a radio signal, searching for service.

- A connection is made with your service provider.

- You select a Web site that you wish to view. 
- A request is sent to a gateway server using WAP.

- The gateway server retrieves the information via HTTP from the Web site.

- The gateway server encodes the HTTP data as WML.

- The WML-encoded data is sent to your device.

- You see the wireless Internet version of the Web page you selected.

Although WML is well suited to most mundane content delivery tasks, it falls short of being useful for database integration or extremely dynamic content. PHP fills this gap quite nicely-integrating into most databases and other Web structures and languages. It's possible to "crossbreed" mime types in Apache to enable PHP to deliver WML content. WML pages are often called "decks". A deck contains a set of cards. A card element can contain text, markup, links, input-fields, tasks, images and more. Cards can be related to each other with links.

When a WML page is accessed from a mobile phone, all the cards in the page are downloaded from the WAP server. Navigation between the cards is done by the phone computer (inside the phone) without any extra access communications to the server.

\section{The E-Learning Platform of THE AOU}

Arab Open University was established in 2002 in the Arabic region, and adopted the open learning approach. AOU has partnerships with the United Kingdom Open University (UKOU) and other national educational institutes, such as MoHE, and international institutions, including UNISCO, to help ensure a high quality of teaching.

An open learning system is defined as "a program offering access to individuals without the traditional constraints related to location, timetabling, entry qualifications." [15].

The aim of AOU is to attract large number of students who can not attend traditional universities because of work, age, financial reasons and other circumstances. The "open" terminology in this context means the freedom from many restrictions or constraints imposed by regular higher education institutions which include the time, space and content delivery methods.

Freed et al. [16] claimed that the "interaction between instructors and students and students to students remained as the biggest barrier to the success of educational media". The amount of interaction plays a great role in course effectiveness [17]. For this purpose and to reduce the gap between distance learning and regular learning, the AOU requires student to attend weekly tutorials. Some may argue that it is not open in this sense; however the amount of attendance is relatively low in comparison with regular institutions. For example, 3 hours modules which require 48 hours attendance in regular universities, is reduced to 12 hours attendance in the AOU.

At the beginning the AOU used the FirstClass system as a computer mediated communication (CMC) tool to achieve a good quality of interaction. The FirstClass tool provides email, newsgroups and conferences as possible mediums of communication between tutors, tutors and their students, and finally between students themselves. The most important reason behind using FirstClass was the tutor marked assignment (TMA) handling services that FirstClass provided. However, the main servers are lo- cated in the UKOU which influences the control process, causes delays, and totally depends on the support in UKOU for batch feeds to the FirstClass system [18].

To overcome these problems, AOU use Moodle nowadays as an electronic platform. Moodle is an open-source course management system (CMS) and learning management system (LMS) used by educational institutes, business, and even individual instructors to facilitate web technology to their courses. A course management system is "often internet-based, software allowing instructors to manage materials distribution, assignments, communications and other aspects of instructions for their courses."[19]. CMS and LMS or virtual learning environments (VLE), are web applications, meaning they run on a server and are accessed by using a web browser. Both students and tutors can access the system from anywhere with an Internet connection. Moodle provides many learning tools and activities such as forums, chats, quizzes, surveys, gather and review assignments, and recording grades as components of its LMS.

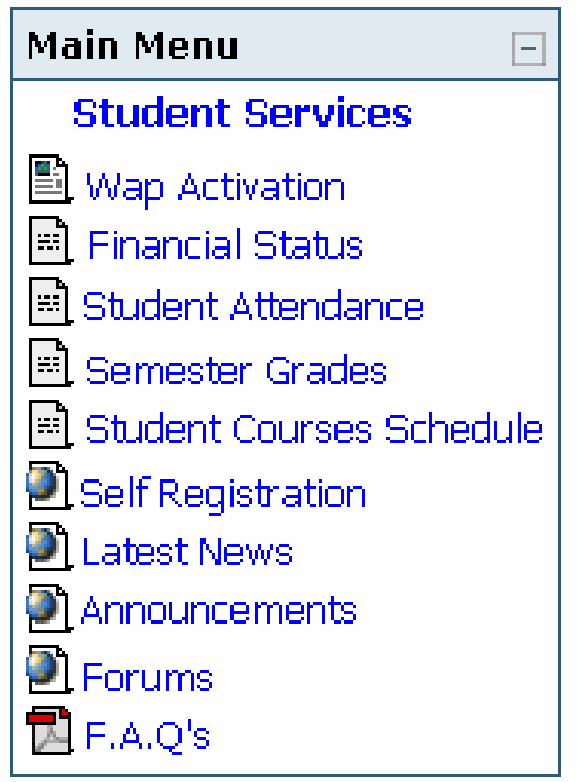

Figure 3. AOU-LMS integrated tools

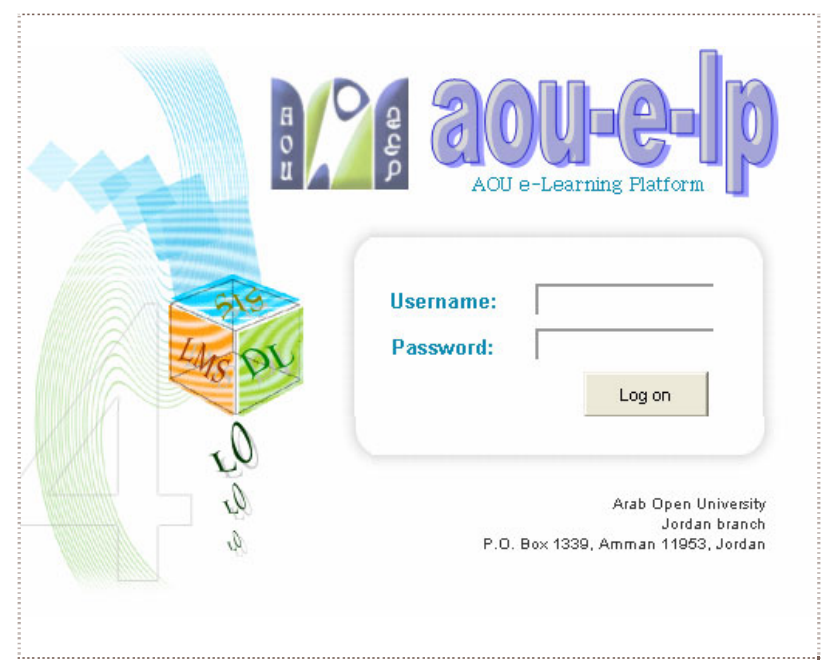

Figure 4. The unified image of the AOU e-learning systems 
Moodle was used in AOU mainly to design a well formed learning management system which facilitates the interaction among all parties in the teaching process, students and tutors, and more over to integrate the LMS with the student information system (SIS).

In addition that Moodle is easy to learn and use, and that it is popular with large user community and development bodies. Moodle is flexible in terms of:

- Multi-language interface,

- Customization (site, profiles),

- Separate group features, and pedagogy.

The unified image of the e-learning platform of the AOU from the starting web page shown in Fig. 4, the users will be able to:

- Connect to the SIS, where they could do online registration, seeing their grades and averages.

- Perform learning activities through the LMS, such as submitting assignments, do online quizzes, etc.

- Retrieve resources through AOU digital library subscriptions.

To fit the AOU requirements and specification, a number of modifications and customizations were made (see Fig. 4), including:

- Log records. Logs are replicated into other isolated tables, to increase performance, and to keep track records for long period, while removing these log records from original tables.

- Some facilities and activities are added.

- Student's attendance and absences sheets are provided.

- Grades customizations (fractions) excel sheets are available.

- Randomly captured assignments for quality assurances purposes.

- WAP (wireless application protocol) services (grades, schedule, financial issues, and news) are presented.

\section{WAP TECHNOLOGY USED IN AOU-LMS}

AOU has a pioneer experience of developing and integrating the well known learning management system Moodle.

One of our recent integrations of our LMS is the use of WAP technology to mediate the system learning tools such as forums, chat rooms, and announcements. In the next paragraph, we will discuss integration opportunities and limitations of WAP technology for supporting a learning community. Recently, El-Seoud et al. [20] presented a framework for a mobile interface for moodle which utilize proper moodle activities over mobiles.

The main goal is to widen the usage of technology in education to make is reachable, feasible, and reachable to the students anytime, and anywhere. Lee [21] explored the potential of WAP technology as an effective online communicating tool when coupled with other tools.

As a component tool of AOU-LMS courses websites, students have the opportunity of using the integrating instructional technology effectively into their classroom practices. There are approximately $25 \%$ of face-to-face tutorial lessons for each course and the remainder of $75 \%$ of the course time is delivered using online e-learning activities. AOU has adopted Moodle, an online learning delivery and management system that allows students to learn independently and tutors to customize the online learning package according to their students' needs. Students are equipped with WAP enabled mobile phones to participate in the e-learning activities.

A mobile telecommunication service provider provides the mobile phones and the WAP services subscriptions. Students have the choice of using the e-learning tools via Moodle from their personal computers or via their WAP enabled mobiles using the WAP technology. All ediscussions took place at the class level, consisting of students and a tutor. In-house software developers developed a WAP-based e-discussion application to allow the students in the study to access the e-discussion forums via their WAP-enabled phones.

In this application, the tutor was able to do the administrative function, namely to manage the forums and his group, and to carry the discussion with his students via the WAP-enabled phones. Students logged on to the ediscussion via their phones to discuss with other classmates and the tutor. They created new threads, viewed threads, replied to and deleted messages. There are at least three forums for each course; extra forums can be added as required. One forum of a particular course is on case studies.

During a study of the WAP services, it was observed that students experienced difficulties in using the WAPenabled phones as a result of slow transmission speed, navigational problems and short battery life. On the other hand, WAP technology offers opportunities for ediscussions in a learning community. It has been observed that WAP technology had helped to build a learning community. We believe that WAP technology have mediated the formation of a closely-knit group where everyone is able to participate and learn from one another. Its mobility is offering the tutor and students anytime-anywhere participation in the e-discussion forums. This opportunity for anytime-anywhere participation might motivate students to participate in the e-discussion forums.

The main limitation of WAP technology is the technical problems of using the WAP-enabled phones. These problems include:

- Short life span of the phone battery,

- Difficulties in logging into the WAP-based forums,

- Slow transmission, failure to send and the need to resend messages,

- Navigational problems, it is difficult to read and browse the messages on the small screen of the phone.

- Difficulties to key in messages using the WAPenabled phones.

Technical problems are not the most critical, but the first, hurdle that must be crossed. Improving the technical capabilities of the WAP-enabled phones would encourage more participation in the WAP-based forums, and might even enhance the quality of WAP-based messages.

When comparing the mobile network to the fixed network there seems to be many limitations, as already discussed. The mobile network also provides unique advantages or features such as the position or location of the 
device and personalization (both user preferences and device capabilities). The WAP language supports these features of Positioning and Personalization. A WAP language component supports User Profiles which contains information on the user preferences and the device capabilities.

Furthermore, current WAP technology makes it best suited to particular aspects of e-learning courses, such as:

- Quick reminders and alerts

- Communication with peers and managers

- Multiple-choice quizzes with immediate feedback

- Daily tips

- Glossary information

- Browsing e-learning course material

- Searching for specific information within a topic

- Links to WAP sites

- Course registration

Tutors and students interact via forums as shown in Fig.5. There are mainly four types of forums as follows:

- News forum is used to announce important dates, such as final exams time table, and other news related to AOU.

- Course forum, is used by the tutor to send lecture notes to all students who are registered in a specific module.

- The tutor group forum as shown in Fig. 5 is used as an interacting media between tutors and students. Any message send by the tutor in the tutor forum could be accessed by all students registered in this module with this tutor. At the same time, if student send a message to the tutor or to another student, this message could be read by all.

- Dialogue forum, is used to add some privacy in student/tutor relationship, in which messages in these case will be not be accessed by all, only between both parties.

The new activity to be added is to ask a student if he/she wants to receive the tutor group forum messages through their mobile devices, if yes, then the sent messages will be delivered to the system as well as the students' mobiles.

In the same manner, the chatting is done through the website; it could be done using the mobile.

Moreover, any announcement via the LMS can be directly transmitted to the intended receivers' mobiles to guarantee a full awareness of such announcements.

\section{REQUIREMENTS AND BENEFITS OF ADOPTING WAP TECHNOLOGY IN EDUCATION}

Computer-based learning environments are increasingly becoming commonplace at colleges and universities. Myers and Talley [22] classify the computer-based technologies into two categories:

1. Online course management systems and specialized collaborative environments that allow electronic communication of classroom instruction materials to students, among students and between student and instructor;

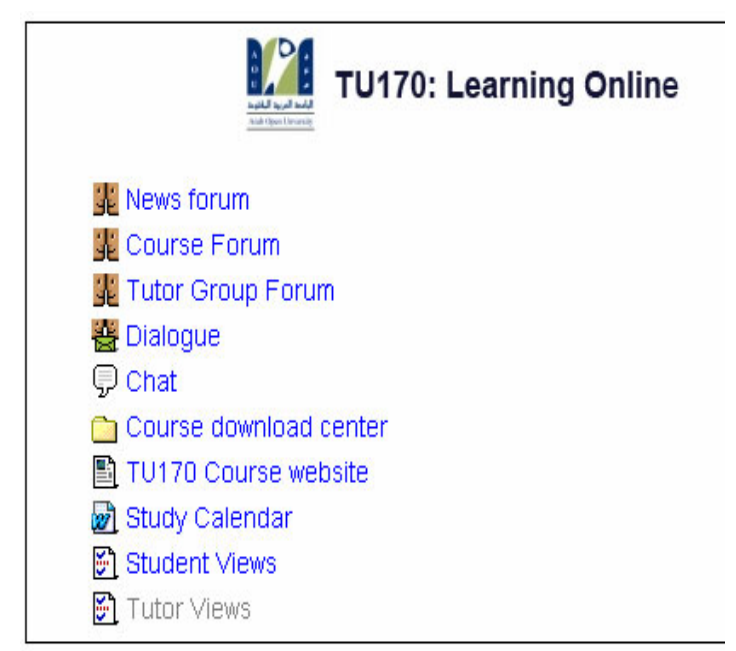

Figure 5. TU170 course (AOU) with its forums

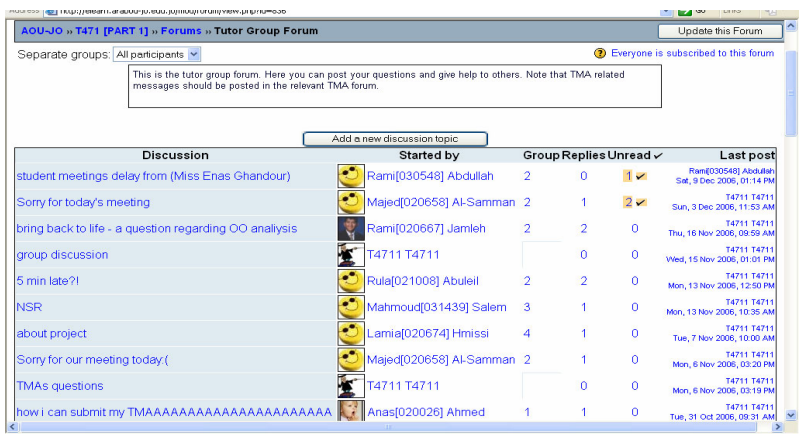

Figure 6. Tutors group forum view

2. Wireless network systems that allow faculty and students with mobile computers to communicate with their campus networks.

Mobile and wireless technology has been served in many domains such as commerce, and education. Mobile learning "m-Learning" is e-learning delivered through mobile computational devices. So mobile learning can provide online learners with capabilities to get instant notification on e-mail, access learning sites, report data from the field, and collaborate with learning colleagues. [1].

M-learning does not replace traditional learning; it just represents another way of learning. Siau and Nah [9] listed the usefulness of mobile technology for both students and tutors. The students' benefits are:

1. The education materials are available for students regardless of where they are;

2. Education materials can be delivered to students based on their needs and preferences.

3. Students can communicate and interact with pee students and educators in real time.

The benefits for tutors are presented by providing a new means of education delivery as well as adding a new dimension for student-tutor interaction. For example, wireless classroom response systems can be integrated into classroom instructions to gather students' responses and provide instantaneous feedback to students on their performance. This could improve classroom interactivity, enhance teaching effectiveness, and promote student learning. 


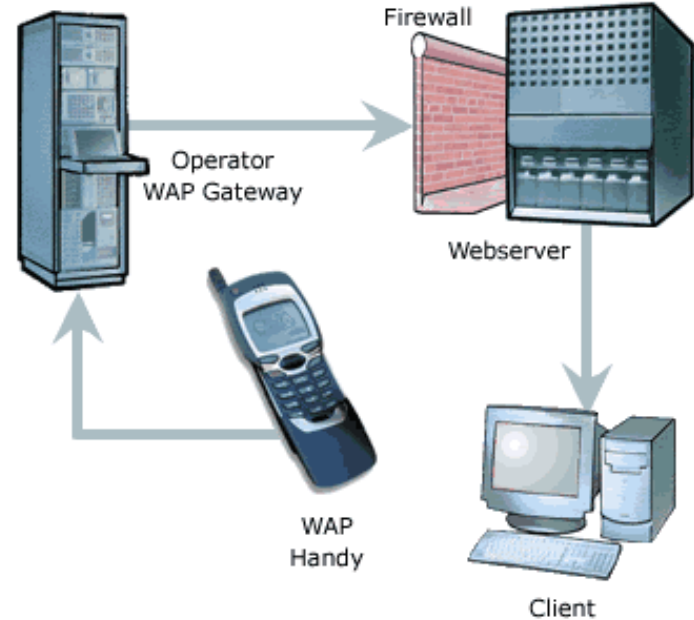

Figure 7. The infra structure of enhancing the mobile technology

The attributes of mobile devices are operating system, large graphical display, touch screens, connectivity, memory, programmability, and personal information manager (PIM) functionality [23]. Recent evolutions on laptop computing have led to what is called TabletPCs, which is digital pen-based mobile PCs that use digital ink enabled software, and it is used in teaching [24], the general structure of enhancing the mobile technology with e-learning is shown in Fig. 7.

However, the availability, mobility, and performance of wireless technology depend on five major areas [25]:

4. Platform, the majority of PDAs and cellular phones being produced have embedded in them some type of Web browsing technology.

5. Connectivity, the true wireless connectivity is wireless Radio Frequency (RF). The wireless communication categories are Wireless Local Area Network (WLAN), and Wireless Wide Area Network (WWW). Training sites at corporations and students at universities use wireless connectivity to facilitate access to information, information exchanges and learning [26].

6. Wireless Middleware, provides services specific to the world of wireless and handheld computing. Wireless middleware services are secure communication management, synchronization, message processing and management tools [23].

7. Back-End System, handheld and wireless computing extends the reach of corporate data and corporate transaction engines. The data stored on a Web site, mainframe, UNIX server, or an Oracle database.

8. Security, in a wireless world, security includes communication links, integrity of the channel, and accuracy of transactions.

\section{CONCLUSION}

This paper has explored the opportunities and limitations of WAP technology in mediating e-learning tools to build a learning community. To make WAP-based discussions more successful online communication technology for education, we must continuously refine our research plans and explore future areas of research. More studies may be conducted to explore the possible ways to make WAP technology a successful social and cognitive tool for facilitating individual learning and enhancing the social construction of knowledge. The technical aspects of the WAP-enabled mobiles may also need to be considered seriously in the future development of WAP technology with respect to e-discussions and/or learning.

In conclusion, WAP is suitable for the creation of mobile learning training course material. The optimization of WAP and the handling of the design challenges make it feasible to use mobile handheld devices for distance learning in real-time. The application developer must always be aware of the user and take into account the usability issues if the application is to be a success. The experience of AOU on enhancing its LMS with WAP technology for a move toward m-learning has been introduced.

\section{FUTURE WORK}

Our future trends are to keep enhancing our m-learning system and its integration with other online system used in the educational institutes. We will also do a complete comparison of infrastructure technologies used as a backbone of m-learning including WAP, 3G, and GPRS. Furthermore, we will do a performance analysis to measure the suitability of using m-learning in education and compare it with other learning technological platforms.

\section{REFERENCES}

[1] F. Mikic, L. Anido, "Towards a standard for mobile technology", Proceedings of the International Conference on Networking, Systems, Mobile Communications and Learning Technologies ICNICONSMCL'06, vol. 0, pp. 217-222, 2006.

[2] K. Kruse, "The benefits of e-learning", http://www.executivewo men.org/pdf/benefits_elearning.pdf, 2003

[3] K. Siau, E. Lim, Z. Shen, "Mobile Commerce - Promises, Challenges, and Research Agenda," Journal of Database Management, vol. 12, no. 3, pp. 4-13, 2001.

[4] J. Krogstie, K. Lyytinen, A. Opdahl, B. Pernici, K. Siau, K. Smolander, "Mobile Information Systems - Research Challenges on the Conceptual and Logical Level," Lecture Notes in Computer Science - Advanced Conceptual Modeling Techniques, vol. 2784, pp. 124-135, 2003.

[5] K. Siau, Z. Shen, "Building Customer Trust in Mobile Commerce," Communications of the ACM, vol. 46, no. 4, pp. 91-94, 2003. (doi:10.1145/641205.641211)

[6] H. Galanxhi-Janaqi, F. Nah, "U-Commerce: Emerging Trends and Research Issues," Industrial Management and Data Systems, vol. 104, no. 9, pp. 744-755, 2004. (doi:10.1108/02635570410567739)

[7] K. Siau, Z. Shen, "Mobile Commerce Applications in Supply Chain Management, "Journal of Internet Commerce, vol. 1, no. 3, pp. 3-14, 2002. (doi:10.1300/J179v01n03_02)

[8] K. Siau, Z. Shen, "Mobile Communications and Mobile Services," International Journal of Mobile Communications, vol. 1, nos. 1/2, pp. 3-14, 2003. (doi:10.1504/IJMC.2003.002457)

[9] F. Nah, K. Siau, H. Sheng, "The Value of Mobile Applications: A Utility Company Study," Communications of the ACM, vol. 48, no. 2, pp. 85-90, 2005. (doi:10.1145/1042091.1042095)

[10] H. Sheng, F. Nah, K. Siau, "Strategic Implications of Mobile Technology: A Case Study Using Value-Focused Thinking," Journal of Strategic Information Systems, vol. 14, no. 3, pp. 269290, 2005. (doi:10.1016/j.jsis.2005.07.004)

[11] K. Siau, F. Nah, "Mobile Technology in Education", IEEE Transactions on Education, vol. 49, No.2, 2006 (doi:10.1109/ TE.2006.875792)

[12] A.L. Foster, "Can You Hear Me Now?" The Chronicle of Higher Education, vol. 52, no. 12, p. A32, 2005.

[13] J. Chen, Kinshuk, "Mobile Technology in Educational Services," Journal of Educational Multimedia and Hypermedia, vol. 14, no. 1, pp. 91-109, 2005.

[14] S. Sharma, F. Kitchens, "Web Services Architecture for MLearning", The Electronic Journal of e-Learning, vol. 2, no. 2, 2004 
[15] P. Karampiperis, D. Sampson, "Designing Learning Services for Open Learning Systems Utilizing IMS Learning Design", Proceeding of $4^{\text {th }}$ IASTED Int. Conf. on web-based Education (WBE 2005), Swaziland, pp. 165-170, 2005

[16] K. Freed, "A History of Distance Learning", http://www.mediavisions.com/ed-distlrn.html, 2004

[17] A.P. Rovai, K.T. Barnum, "On-line course effectiveness: an analysis of student interactions and perceptions of learning", Journal of Distance Education, vol. 18, no. 1, 57-73, 2003.

[18] S. Hammad, A.E. Al-Ayyoub, T. Sarie, "Combining existing elearning components towards an IVLE". EBEL conference, 2005.

[19] M.C. Lohman, "Effects of Information Distributions Strategies on Student Performance, and Satisfaction in a Web-Based Course Management System", International Journal for the Scholarship of Teaching and Learning, vol. 1, no. 1, pp. 1-17, 2007.

[20] S. Abou El-Seoud, Ashraf M. Ahmad, H. El-Sofany," Mobile Learning Platform Connected to Moodle Using J2ME", International Journal of Interactive Mobile Technologies (iJIM), Vol 3, No 2, pp. 46-54, 2009

[21] C. Lee, "Exploring the Potential of WAP Technology in Online Discussion", Association for Educational Communications and Technology, 27th, Chicago, IL, October 19-23, 2004.

[22] S. Myers, D. Talley, "Looking beyond the Whiz-bang technology: using mobile learning technology tools to improve Economic instruction". The ASSA, USA, 2007
[23] Sbihli, S. Developing a successful wireless enterprise strategy. New York: Wiley Computer Publishing, 2002.

[24] B. Abu-Shawar, J. Al-Sadi, \& A. Hourani, "Integrating the Learning Management System with other Online Administrative Systems at AOU", Proceedings of The International Conference on Algorithmic Mathematics and Computer Science (AMCS'06), USA, June 22-25, 2006

[25] B. Sasidhar, B. Kumar. "The effects of mobile devices and wireless technology on E-learning", Sunway Academic Journal. vol 2, pp. 45-53, 2005.

[26] G. Rogers, J. Edwards. "An introduction to wireless technology. Upper Saddle River”, NJ: Prentice Hall, 2003.

\section{AUTHORS}

J. A. Al-Sadi is the head department of Information Technology and Computing at Arab Open University, Jordan (e-mail: j_alsadi@aou.edu.jo)

B. A. AbuShawar is an instructor in department of Information Technology and Computing at Arab Open University, Jordan (e-mail: b_shawar@aou.edu.jo)

Submitted, January, 17, 2009. Published as resubmitted by the authors on May, 16, 2009. 